\title{
PROPOSTA METODOLÓGICA PARA IMPLANTAÇÃO DO SISTEMA DE GESTÃO DE CUSTOS VOLTADO AO PROCESSO PRODUTIVO INDUSTRIAL
}

\author{
Adriano Pereira da Silva ${ }^{(1)}$ (pereiras.adriano@gmail.com), Francisco Gaudêncio Mendonça Freires ${ }^{(2)}$ \\ (gaudenciof@yahoo.com) \\ (1) Universidade Federal da Bahia (UFBA); Programa de Engenharia Industrial \\ (2) Universidade Federal da Bahia (UFBA); Departamento de Engenharia Mecânica
}

RESUMO: A existência de um sistema de custo adequado é um dos melhores e mais utilizados instrumento de informação que auxilia na melhoria dos processos internos e na tomada de decisões, apresentando técnicas voltadas para a apuração do custo dos produtos e serviços que atende as necessidades legais e fiscais, permite aos gestores uma análise econômica da empresa, baseada em valores reais, avaliando o desempenho para a tomada de decisões. Assim, a partir de uma revisão bibliográfica, esse trabalho tem como tema apresentar os procedimentos necessários para implantação do sistema de custo integrado voltado ao processo produtivo industrial e seus respectivos objetivos dessa proposta de implantação, traduzidos em levantar as principais fontes de pesquisa pertinentes ao tema, expor as exigências da legislação para a utilização do sistema de custo integrado, ademais, elencar os procedimentos necessários para a implantação do sistema de custo integrado e coordenado com a produção industrial. Concluindo-se a partir de então, a importância dessa proposição no tocante de mitigar as falhas de um sistema produtivo, aderindo a mecanismos que convirjam no cumprimento das metras das empresas, visto pela tentativa de estabelecer parâmetros de redução de custos.

PALAVRAS-CHAVE: MELHORIA DOS PROCESSOS, PROPOSTA DE IMPLANTAÇÃO, REDUÇÃO DE CUSTOS.

\section{CYCLE TIME MEASUREMENT: A CASE FROM THE APPLICATION OF CHRONOANALYSIS ON A AUTO PARTS ASSEMBLY}

ABSTRACT: The existence of an adequate cost system is one of the best and most used information tool that helps improve internal processes and decision making, presenting techniques aimed at determining the cost of products and services that meets legal needs. and tax, allows managers to make an economic analysis of the company based on real values, evaluating performance for decision making. Thus, based on a literature review, this paper aims to present the necessary procedures for the implementation of the integrated cost system aimed at the industrial production process and their respective objectives of this implementation proposal, translated into survey the main research sources relevant to the theme., expose the requirements of the legislation for the use of the integrated cost system, and list the necessary procedures for the implementation of the integrated cost system and coordinated with industrial production. Concluding from then on, the importance of this proposition in terms of mitigating the failures of a productive system, adhering to mechanisms that converge in the compliance with the companies' metrics, seen by the attempt to establish cost reduction parameters.

KEYWORDS: PROCESSES IMPROVEMENT, PROPOSAL FOR IMPLEMENTATION, COST REDUCTION. 


\section{INTRODUÇÃO}

A partir do cenário econômico atual, as organizações buscam constantemente alternativas que tragam vantagens competitivas, mediante ao acirrado mercado empresarial, na qual, cada vez mais a lucratividade se torna latente nesta disputa de sobrevivência. Por conseguinte, uma das medidas é primordialmente a redução dos custos, visto que, o desempenho e resultado organizacional está interligado ao processo de gestão, assim, é necessário associar o conceito de gestão de custos diretamente ao processo produtivo industrial. Desta forma, baseando-se na delimitação do tema abordado, pretende-se responder a seguinte pergunta: Quais os métodos necessários para a implantação do custo integrado ao sistema de produção industrial?

Nesse sentido, o presente estudo remete-se a relevância que o cumprimento das metras das empresas, visto pela tentativa de estabelecer parâmetros de redução de custos. Encontrar a forma exata neste sentido é um desafio que deve ser estabelecido com um planejamento bem elaborado. Para ludicibus (2009), é através das informações fornecidas pela contabilidade que se pode obter condições de reduzir custos de forma adequada, buscando as melhores soluções, tornando a empresa mais competitiva, consequentemente, aumentando seus resultados. A redução de custos não é mais um diferencial em uma empresa, atualmente se torna uma obrigação.

Portanto, o objetivo geral desta pesquisa é: Propor uma metodologia para implantação do sistema de gestão de custos voltado ao processo produtivo industrial. De forma análoga, os objetos específicos são: Levantar os referenciais bibliográficos relacionados aos custos e sistemas de custeio (conceitos, técnicas etc.); Apresentar as exigências da legislação para a utilização do sistema de custo integrado; Elencar os procedimentos necessários para a implantação do sistema de custo integrado e coordenado com a produção industrial; Evidenciar a importância que o sistema de custo integrado a produção industrial.

Os métodos de pesquisa a serem utilizados serão de pesquisa bibliográfica, pois, será realizado o levantamento do assunto objetivo da pesquisa através de livros, revistas, legislação, trabalhos de conclusão. O objetivo é apontar todos os procedimentos necessários para a implantação do custo integrado ao sistema produtivo, bem como a importância desse sistema para a geração e análise das informações gerenciais.

\section{REFERENCIAL TEÓRICO}

A manutenção de um sistema formal de contabilização dos custos de produção visa atender fatores importantes ao processo da organização, como o controle gerencial e o atendimento à legislação exigível. Logo, este referencial teórico busca elucidar os conceitos 
fundamentais para esta estruturação metodológica.

\subsection{Sistemas de produção industrial}

A ideia de otimização teve início no século XVIII na Inglaterra junto a Revolução Industrial com a mecanização do sistema de produção, vindo a tornar os métodos de produção mais eficientes com o uso de máquinas. Desta forma acelerou o ritmo de produção, deixando os preços mais baixos e estimulando o consumo, tendo como uma das principais consequências o aumento de desemprego. Além das máquinas as empresas passaram a se caracterizar pela utilização do trabalho em série, realizado em etapas e especializado onde cada trabalhador realizava uma ação.

Outra fase que caracteriza uma das maiores inovações tecnológicas na era Industrial foi a linha de montagem, criada por Henry Ford na fabricação de automóveis Ford, que reduziu mais ainda o tempo de produção de peças, tendo como consequência um acréscimo na produtividade. Assim, as linhas de montagem são utilizadas desde então no processo de produção em série, para que o produto em fabricação seja deslocado ao longo de postos de trabalho, mas a sua eficiência depende da combinação de quatro condições indispensáveis: componentes padronizados, movimento mecânico, equipamento de precisão e processos padronizados (TUBINO, 1997).

A dimensão do produto influencia a concepção de uma linha de montagem pois vai restringir o número de produtos que podem existir em cada posto de trabalho afetando por sua vez o desempenho do trabalhador. Se o produto é de grandes dimensões isto implica uma dependência entre os postos de trabalho (DAVIS et al., 2001).

Em geral, o aumento da produtividade é um dos principais fatores que permite ganhar competitividade no mercado, e para isso acontecer é necessária uma otimização no processo, tendo como finalidade eliminar o desperdício e melhorar o fluxo. Oishi e Fontanini (1997) comenta que a administração estratégica por produtividade total é uma das maneiras de definir os propósitos e objetivos da empresa, desenvolvendo ações que possibilitem as concretizações destas expectativas. O autor explica que os fatores essenciais estratégicos como técnicas para otimização de processos, mantêm um relacionamento constante com indicadores de satisfação dos clientes e ações dos colaboradores.

Moreira (1998), aborda os conceitos da administração da produção e operações colocando em destaque o processo de tomada de decisão, projeto do sistema de produção, operação e controle do sistema de produção. Desta forma, devido às técnicas existentes para otimização de processos em indústrias automobilísticas, a busca das melhores técnicas para otimização de processo, através de técnicas eficazes se torna imprescindível para conciliar a produtividade e a ergonomia dos postos de trabalho. Tendo como base a pesquisa de 
documentos e procedimentos da empresa automotiva.

Portanto, é de grande importância o conhecimento das melhores técnicas para otimização de processos em indústrias automobilísticas, pois uma vez aprimorando esse conhecimento, se verifica a certeza de uma boa produtividade e satisfação dos funcionários.

\subsection{Sistemas produtivos}

No século XIX, Frederick Winslow Taylor conhecido como F.W. Taylor, engenheiro mecânico, foi considerado pai da Administração Científica por propor a utilização de métodos científicos cartesianos, caracterizados pela ênfase nas tarefas ultra especializadas e repetitivas, objetivando o aumento da eficiência no nível operacional.

Taylor revolucionou os processos tradicionais dos métodos de trabalho, através da aplicação de "métodos científicos" a muitas empresas norte-americanas. Muitos métodos de Taylor não eram em si originais. A originalidade estava na aplicação destes métodos com a visão do engenheiro, o que até então era considerado domínio do costume, da tradição, do personalismo e da política (LACERDA, 2007).

Segundo Lacerda (2007), Taylor estimou que a produção de cada operário era somente um terço do que poderia ser. A esta restrição de produção, ele denominou de vadiagem sistemática. A vadiagem sistemática era um problema que vinha de muito tempo.

Em contrapartida, para Taylor a culpa não era dos empregados e sim da administração, pois, era sua função projetar as atividades de maneira apropriada e oferecer incentivos adequados para estimular a produção operária. Esta abordagem foi transformada em numa filosofia que passou a ser conhecida como administração científica. Do seu livro, Princípios da Administração Cientifica, Taylor via a administração científica de modo amplo, visto que a administração cientifica consiste fundamentalmente de certos princípios gerais amplos, uma certa filosofia, que pode ser aplicada de muitos modos, e uma descrição do que qualquer homem ou homens podem acreditar ser o melhor mecanismo para aplicação destes princípios gerais, o que pode de modo ser confundido com os próprios princípios (TUBINO, 2004).

O primeiro a colocar em prática seus princípios foi o Norte-Americano Henry Ford na sua empresa Ford Motor Company. Em seguida. Criou-se o processo que veio a ser conhecido como fordismo, no qual aplicou à risca os princípios de padronização e simplificação do taylorismo. (OHNO, 1988). 


\subsection{Aspectos fundamentais de custos}

O conhecimento e o domínio das técnicas de apuração de custos são fundamentais para um gerenciamento eficiente e eficaz visando a continuidade de uma empresa. Schier (2011), explica que todas as empresas devem; conhecer, administrar e controlar com muita propriedade os custos e despesas gerados para a produção e comercialização de seus produtos ou serviços. Portanto, a gestão de custos tem como objetivos principais: Apuração do custo dos produtos principais; Atendimento às exigências contábeis; Atendimento às exigências fiscais; Controle de custos da produção; Melhoria e eficiência de processos e eliminação de desperdícios; Auxilio na tomada de decisões gerenciais; Otimização e eficiência de resultados.

Nesta perspectiva, as situações que envolvem esses procedimentos geralmente requerem o entendimento e a análise dos resultados das atividades inerentes ao processo de gestão de custos. Assim, para facilitar a compressão acerca de determinado processo, identifica-se condições específicas, como: gasto, desembolso, investimento, custo, despesa e desperdício. Nessa abordagem, Martins (2003), trata sua respectiva terminologia:

Gasto: Compra de produto ou serviço qualquer, que gera desembolso imediato ou futuro para a empresa, representado por entrega de ativos (normalmente dinheiro). Os gastos ocorrem em todo momento e em qualquer setor da empresa. Este conceito tem amplo emprego e se aplica a todos os bens e serviços adquiridos.

Desembolso: Pagamento resultante da aquisição de bem u serviço. São saídas em dinheiro ou cheque que ocorrem devido ao pagamento de uma aquisição efetuada à vista ou de uma obrigação assumida anteriormente. Pode ocorrer antes, durante ou após a entrada da utilidade comprada, sendo, portanto, defasado ou não do momento gasto.

Investimento: Gasto ativado em função da sua vida útil ou de benefícios atribuíveis a futuro(s) períodos(s), o que significa aquisição de bem ou produto que gerará benefício financeiro no futuro. Todos os sacrifícios feitos pela aquisição de bens e serviços (gastos), que são "estocados" nos ativos da empresa para baixa ou amortização, quando de sua venda, de seu consumo, de sua desvalorização ou de sua desvalorização.

Custo: Gasto relativo a bem ou serviço utilizado na produção de outros bens e serviços. É importante observar que há um mecanismo interativo entre essas condições operacionais, pois, é também um gasto. Este só é reconhecido como custo no momento da utilização dos fatores de produção para fabricação de um produto ou execução de um serviço. Ou seja, aquilo que é utilizado na produção - matéria-prima consumida, materiais auxiliares, mão-de-obra produtiva.

Despesa: Bem ou serviço consumido, direta ou indiretamente, para a obtenção de receitas. A comissão do vendedor, por exemplo, é um gasto que se torna imediatamente uma despesa. As despesas são itens que reduzem o patrimônio líquido e que têm a característica de 
indicar um sacrifício no processo de obtenção de receitas.

Perda: Bem ou serviço consumido de forma anormal e involuntária. É diferente de custos, exatamente por sua característica de anormalidade e voluntariedade, a vista que não é um sacrifício feito com intenção de obtenção de receita.

Desperdício: Gasto incorrido no processo produtivo ou geração de receitas, que possa ser eliminado sem prejuízo da qualidade ou quantidade dos bens, serviços ou receitas geradas. No âmbito da operacionalidade, encontra-se aspectos relativos aos modelos, métodos, estratégicas e aos posicionamentos, entre outros, que significam a prática da gestão de custos.

\section{MODELO PROPOSTO}

Para Moreira (2015), a implantação de um sistema de custo integrado ao sistema produtivo requer da empresa uma reestruturação e controles internos bem elaborados. Nesta perspectiva o primeiro passo é dividir a empresa em departamentos, também chamados de centros de custos, estes podem ser produtivos, auxiliares ou administrativos. Conforme Martins (2003), os departamentos são criados para dividir a empresa em áreas, com o objetivo de descentralizar a administração, atribuindo autonomia e responsabilidade ao coordenador de cada centro de custo e ao mesmo tempo possibilitando a avaliação de sua gestão.

A departamentalização possibilita o controle, análise e a avaliação dos custos indiretos, facilitando a alocação dos custos de forma mais adequada. Além disso, os centros de custos auxiliam no momento de apuração dos custos, pois facilita o cálculo do custo das atividades de cada setor, que correspondem a um determinado produto, não permitindo que um departamento e/ou produto seja responsável pelos custos de outro. Cada setor deve ter um procedimento adequado para que a informação seja exata, é indispensável que haja organização para facilitar a avaliação correta dos custos. Assim, Biasio (2014), expressa da seguinte forma:

Departamentalização é a divisão da empresa em centros de custos, objetivando alocar em cada um deles os seus respectivos recursos produtivos (máquinas, equipamentos, pessoas etc.) e gastos por eles provocados visando apurar diversos parâmetros de desempenho por centro (custo, tempo de produção, produtividade, resultado, eficiência, eficácia), possibilitando entre outras coisas calcular o custo das atividades produtivas, dos produtos fabricados e avaliar a gestão administrativa do responsável de cada centro de custo. (BIASIO, 2014, p.53).

Para dividir uma empresa em departamentos é preciso observar as atividades e os equipamentos que a empresa utiliza. Após a divisão, deve-se fazer um mapeamento identificando todos os centros de custo e os recursos produtivos utilizados em cada centro como máquinas, equipamentos, atividades e pessoas. O próximo passo é alocar os custos em seus respectivos centros. Primeiro é preciso alocar o maior número de custos diretos e os que não forem 
possíveis, usar como critério para alocação a causa que gerou determinado custo.

\subsection{Condições básicas de implantação}

O principal objetivo das empresas é a lucratividade, e para isso buscam cada vez mais a redução de custos. Encontrar a forma exata para reduzir custos de uma empresa é um desafio que deve ser estabelecido com um planejamento bem elaborado. Deste modo, Nakagawa (1991), informa alguns fatores devem ser incorporados:

Fatores Comportamentais: Mediante experiencias adquiridas nas situações de mudanças organizacionais, nos períodos de reformulação de sistemas em vigor e de implantação de novos sistemas, a administração de pessoal e psicologia organizacional convergem-se para tratar problemas de relações humanas em face dessas mudanças. Portando, na tarefa de implantação ou de reformulação não pode entrar em conflito com as relações humanas que thes são desfavoráveis, visto que, deve-se capitalizar essas forças, para que se somem aos esforços. Assim, uma das maneiras mais fáceis de alcançar esse objetivo, nas tarefas de planeamento, projeto e implantação, é envolver pessoal que vai manusear e trabalhar com o novo sistema.

Fatores Técnicos: Uma das razões da ineficiência da execução de um sistema de gestão de custos está presente na má organização da empresa, pois, o trabalho é desenvolvido por outros sistemas internos, como o sistema de materiais, de pessoal, contabilidade e produção, considerados os mais importantes. Desta forma, deve-se articular com o setor responsável de Organização e Método, promovendo a correta colha ou recebimento de dados. Em paralelo, o sistema de custos deverá ser instalado de tal modo que possa servir de correção automática dos desvios e de ocorrências não planejadas. Por conseguinte, ao receber os dados de componentes funcionais e operacionais, ou quaisquer outros transformados em informações gerenciais, que servirão como base para tomada de decisão.

\subsection{Etapas para o projeto de implantação}

Prever e controlar custos e resultados é necessário para que a organização obtenha sucesso nos seus planos. Tendo em vista a importância do gerenciamento de custos, surge a necessidade de moldar os processos de acordo com as intenções da sua empresa. Assim, Lang (1977), especifica o levantamento da organização, separando os componentes em operacionais e administrativos, definindo a autoridade, a natureza, o alcance e as limitações das atividades, bem como as responsabilidades de cada componente. Deste modo, Lang (1977), identifica alguns passos devem ser seguidos na projeção e implantação de um sistema de custos, tais como: Definir parâmetros e unidades de mensuração que possam medir o volume de cada um dos 
componentes organizacionais, estabelecidos primeiramente; Analisar o comportamento dos custos e despesas de cada componente diante das bases de volume determinados posteriormente; Familiarizar com o plano de investimentos, expansão, reorganização e remanejamento das máquinas, dos equipamentos e dos departamentos; Analisar e reformular, se necessário, parte do sistema de materiais para que o sistema de custos a ser criado ou reorganizado passo nesse se integrar; Analisar e reformular, se for o caso, o sistema de mão-deobra, integrando-o com o sistema de custos; Estudar os modelos de contabilidade já em uso na empresa com o objetivo de usá-lo na integração do sistema de custos; Analisar o sistema de controle patrimonial - Para as finalidades de implantação de sistemas de custos, entende-se como controle patrimonial todas as ações, órgãos, objetos e registros que objetivam a administração dos itens patrimoniais da empresa, tais como os ativos permanentes. Inserir o sistema de planejamento, incluindo principalmente o orçamento da empresa, deve ser integrado ao sistema de custos; Projetar relatórios; Desenvolver o sistema de custos adequado às condições da empresa.

\subsection{Sistema de informação}

Os sistemas de custos funcionam como um centro processador de informações, que colhe, ou recebe, dados monetários e não-monetários, externos e internos, organiza-os e analisaos, gerando informações gerenciais de custos, destinados a auxiliar os vários níveis da gestão empresarial a se desincumbirem de suas funções e responsabilidades.

Assim como os avanços da tecnologia de informações, os sistemas têm possibilitado cada vez mais a construção de sistemas de custos que se adaptam a grande maioria das empresas, abreviando o processo de implantação de sistemas informatizados de custos.

(...) informações geradas pelo sistema de custo (...), exige um cuidadoso trabalho na implantação dos sistemas de custo e, consequentemente, na sua administração e utilização. As empresas, de um modo geral, tendem a classificar as informações de seus custos como confidenciais, contribuindo ainda mais para a necessidade de cuidados na implantação e na utilização do sistema de custos. (PADOVEZE, 2003, p.86)

A administração do sistema de informação que integra custos e contabilidade deve ser de responsabilidade do controller da empresa, ou contador geral. Isso porque só um profissional especializado tem compreensão exata da necessidade de integração das informações de custo com as informações produtivas, contábeis e financeiras da empresa.

O sistema de informações integrado com a contabilidade tem a função de abastecimentos para toda a empresa. Nele deve conter a estrutura do produto, os processos de fabricação, sistema de compras, movimentação de estoques, folha de pagamento, controle patrimonial, 
entre outros, formando um grande conjunto de informações úteis para a controladoria.

Padoveze (2003), define os usuários das informações fornecidas pelo sistema, além da controladoria e os responsáveis pelo processo produtivo, podemos citar: compradores, engenheiros, vendedores, administradores de comercialização, pessoal de marketing e responsáveis pelos estoques e controles de produção.

\subsection{Aplicação das técnicas de organização e método}

Conforme Guerrige (1978), os sistemas de custos, de orçamento, de contabilidade e de controle financeiro, normalmente, estão baseados num corpo comum que constituído pelas funções e operações originais. Os dados dos documentos representativos dessas operações serão muito mais úteis para a empresa, pois, o uso dos sistemas eletrônicos de processamento de dados estabelece uma facilidade dentro do gerenciamento da rotina.

Diante do exposto, Monzo (2003), explicita que o boletim diário de caixa indica algumas modificações praticadas sistemicamente, visto que, essas reformulações resultam principalmente do emprego uniforme da classificação contábil baseada num Plano de Contas, especialmente preparado para esse fim, num positivo esforço de integração, permitindo a preparação simultânea de mapas de acompanhamento orçamentário, de um fluxo de caixa gerencial e de diversos mapas contábeis. Assim sendo, os produtos do sistema, assim integrado, ainda permitem fazer a reconciliação entre os resultados obtidos pelo orçamento, pelo fluxo de caixa e pela contabilidade.

Primordialmente, a estrutura metodológica deve seguir e implantar um serviço de auditoria do sistema de custos. Uma das finalidades, além das informações de feed-back que recolherá e além de verificar as rotinas praticadas estão sendo fielmente seguidas, será o estudo periódico do uso dos relatórios produzidos pelo sistema que, na realidade, se constituem na sua razão de existência. Por conseguinte, o serviço de auditoria terá a atribuição de, continuamente, revisar a utilidade dos diversos relatórios de custos, no sentido de observa se todo ou parte do relatório pode ser descontinuado ou se pode ser reformulado para atender às novas exigências por parte do usuário.

Diante deste contexto, Oliveira e Perez (2000), expõe a importância do manual de custos, sendo verificados os seguintes itens: Objetivos do Sistema; Abrangência; Principais problemas; Critérios de rateio; Critérios de acumulação; Métodos de contabilização; Integração com outras funções; Classificação dos custos; Sistemas de custeamento; Relatórios; Principais usos dos relatórios; Sistema de retro informações; Arquivo de dados. 


\subsection{Composição do estoque de materiais}

Conforme Crepaldi (2002), o custo de aquisição de uma mercadoria ou material inclui todos os gastos necessários para que seja entregue na empresa compradora, bem como os custos de transporte e de seguro. Com relação aos impostos incidentes na compra de mercadorias podem ou não compor o custo das mercadorias, isso vai depender da forma de tributação de cada empresa, e do produto que está sendo adquirido. Na compra de mercadorias e produtos, os impostos que são compensáveis e recuperáveis, devem ser deduzidos do custo. Sendo assim, os valores dos impostos pagos na aquisição das matérias- primas e demais materiais utilizados na produção não compõem o custo do produto e o custo da contabilização da compra é realizado pelo valor líquido.

Oliveira e Perez Jr. (2000) defende que as compras de matérias-primas, material de embalagem e outros materiais utilizados na produção, devem ser acompanhados por uma nota fiscal de compra, que deverão ser escriturados no livro fiscal de entradas. O custo da mercadoria contida na nota fiscal de entrada deve ser contabilizado em valores líquidos, nas contas de estoque, ou seja, sem os impostos recuperáveis, aumentando assim os valores dos materiais estocados.

Não obstante, a venda dos produtos fabricados gera a contabilização de todos os lançamentos ligados à venda e relatórios gerenciais, que auxiliam na tomada de decisões. Em Passarelli e Bomfim (2006), estabelece que a contabilização é realizada nas contas de receita, gerando valores a receber de clientes e tributos referentes à venda como: IPI (Imposto sobre Produtos Industrializados), ICMS (Imposto sobre Circulação de Mercadorias e Serviços), PIS (Programa de Integração Social) e COFINS (Contribuição para Financiamento da Seguridade Social) (no caso de empresas tributadas pelo lucro real), contabilizados em valores a pagar e deduzidos da receita de venda. Os produtos vendidos devem ser acompanhados por uma nota fiscal de venda, que deverá ser escriturada no livro fiscal de saídas.

Crepaldi (2002), consta que o CPV (custo dos produtos vendidos) é contabilizado em uma conta própria, e é deduzido da receita bruta juntamente com os impostos, obtendo como resultado a receita líquida. A contabilização da contrapartida do CPV é conta de estoque, pois no momento da venda é atualizado o estoque, com a baixa imediata do custo correspondente ao produto vendido.

Oliveira e Perez Jr. (2002) mencionam que, além das notas fiscais de saída, também devese considerar os movimentos de estoque, por meios de requisições de produção, onde através delas são movimentadas e contabilizadas as quantidades físicas e em valores de estoque. Todas essas contabilizações geram relatórios que auxiliam na tomada de decisões. 


\subsection{Contabilidade aplicado a gestão de custos}

Segundo Moreira (2015), o sistema de custo integrado e coordenado com a contabilidade caracteriza-se pelo conceito de os valores referentes à matéria-prima, mão de obra e custos gerais de fabricação a serem apoiados em escrituração contábil. Além de permitir o levantamento de estoques de materiais, produtos em elaboração e produtos prontos sejam realizados periodicamente, podendo avaliá-los segundo os custos efetivamente incorridos, evitando a supervalorização dos estoques, que acarreta no aumento da carga tributária.

Se a utilização do método integrado redundar num menor valor do estoque, e a manutenção na empresa de um setor de custo excessivamente onerosa, convém integrar o custo à contabilidade. Com isto se consegue uma valorização do estoque menor, um lucro contábil menos expressivo e consequentemente um imposto de renda mais reduzido. (BERTÓ E BEULKE, 2005, p.165).

Todas as informações existentes na contabilidade devem ter respaldo de documentação, podendo o fisco confirmar os valores existentes na contabilização dos custos.

[...] o primeiro estágio da integração constitui sempre, necessariamente, o dos valores monetários da contabilidade geral e da contabilidade de custos, em critérios já detalhados. É assim, imprescindível que os valores atribuídos às contas de produção no período, pela contabilidade geral, encontrem correspondência nos valores apropriados pela contabilidade de custos aos diversos setores da área industrial. (BERTÓ E BEULKE, 2005, p.165).

O levantamento dos valores correspondentes da matéria-prima, dos gastos gerais e dos estoques é elaborado com base na contabilização das notas fiscais de entrada (compras), notas fiscais de saída (vendas) e requisições de produção. Já os valores correspondentes a mão de obra, são apurados com base nos dados relacionados com a folha de pagamento. Segundo Crepaldi (2002), o lançamento dos valores nas contas contábeis e nos centros de custos tem como objetivo de apurar o custo de produção, de cada centro de custo, visando calcular o custo hora de cada atividade e posteriormente, atribuir uma parcela do custo dessa atividade a cada produto fabricado, na proporção do tempo que ele utilizou em cada atividade.

\subsection{Princípios legais}

Os dados e resultados gerados por um sistema de custo podem divergir, em valores maiores ou menores, com relação aos dados constantes na contabilidade, e o principal motivo dessas divergências é o enfoque gerencial da contabilidade de custos. Tendo em vista esse problema, o Governo criou uma legislação específica, para a integração da contabilidade de 
custos com a contabilidade geral, tornando as informações mais coerentes e coordenadas. Essa legislação é constituída dos artigos 13 e 14 do Decreto Lei $n^{\circ}$ 1.598/77, destacados como os mais importantes por Passarelli e Bomfim (2006). A legislação estabelece normas para a apuração do custo de produção e para a avaliação dos estoques de empresas que utilizam o custo integrado com a contabilidade sujeitas a tributação pelo lucro real; essas normas refletem na determinação do lucro líquido e avaliação de inventário.

De acordo com Oliveira e Perez Jr. (2006), entende-se por sistema de custo integrado e coordenado com a contabilidade com base no Decreto Lei $n^{\circ} 1.598 / 77$, aquele que:

a) apoia-se em valores originados da escrituração contábil, para a apuração dos custos com matérias-primas, mão de obra e custos indiretos de fabricação;

b) permite através da determinação contábil, o valor dos estoques de matérias-primas, materiais de embalagem e outros materiais auxiliares, produtos em elaboração e produtos acabados, ao final do mês;

c) é apoiado em livros auxiliares, fichas ou formulários contínuos ou mapas de apropriação ou rateios, mantidos em boa guarda e de registros coincidentes com aqueles constantes da escrituração principal;

d) permite avaliação dos estoques existentes na data de encerramento do período base de apropriação de resultados segundo os custos efetivamente incorridos.

Passarelli e Bomfim (2006), destacam como os mais importantes relacionados com os critérios para determinação dos custos de bens e avaliação dos estoques. Assim, $\mathrm{O}$ artigo 13 do Decreto Lei $n^{\circ}$ 1.598/77 aborda os custos na aquisição de mercadorias e na produção dos bens ou serviços. O custo de aquisição de mercadorias destinadas à revenda compreende o transporte, seguro e tributos devidos na aquisição ou importação. Já o custo de produção dos bens ou serviços compreende o custo da matéria-prima e outros bens ou serviços aplicados ou consumidos na produção; o custo de mão de obra aplicado na produção inclusive supervisão e manutenção; custo de locação, reparos e depreciação referente à produção; os encargos de amortização; e encargos de exaustão dos recursos naturais; e também aquisição de bens de consumo eventual quando exceder $5 \%$ do custo total dos produtos vendidos no exercício anterior, poderá ser registrado como custo.

No artigo 14, do mesmo decreto, é abordada a determinação do custo dos bens, onde o custo, das mercadorias e das matérias-primas, será determinado com base no registro de estoques de acordo com o livro de inventário, no fim do período. As empresas que mantiverem o sistema de custo integrado A produção poderão utilizar os custos apurados com base na escrituração para avaliar os estoques dos produtos acabados e dos produtos em fabricação. Já as empresas que não se enquadram no sistema de custo integrado, devem avaliar seus estoques da seguinte forma: o estoque de produtos em elaboração deve ser uma vez e meia o maior custo da 
matéria-prima adquirida no período, ou em $80 \%$ dos produtos acabados; e os produtos acabados devem ser avaliados em $70 \%$ do maior preço de venda no período.

\section{CONSIDERAÇÕES FINAIS}

Os aspectos mais relevantes para propor uma metodologia de implantação do sistema de gestão de custos voltado ao processo produtivo industrial não são propriamente os custos específicos, que são insumos básicos, porém os benefícios alcançados com uma análise bem aplicada e consequentemente desenvolvida. Isso acarreta em conhecer seus custos de produção, mas também saber o que, quando e se devem ou não alterar alguma estratégia para obter resultados mais expressivos e contínuos. De forma análoga, utilizar as informações com estratégias administrativas se torna um fator preponderante para essa especificação.

Diante deste cenário, é de fundamental importância hodiernamente, que as empresas apresentem um estruturado processo de coleta dados, a fim de ter informações ágeis e seguras, pois, paralelo a isto, o desempenho e resultado de uma instituição está interligado com o processo de gestão de custos. Por isso é necessário conhecer especificamente os custos das atividades, assim como sua origem, o que proporciona melhor desempenho econômico.

Em linhas gerais, o sistema de gestão de custo integrado ao processo produtivo industrial permite análise de resultados que refletem a realidade da empresa. Esse método aplicado assertivamente proporciona benefícios e a exatidão, tais como nas decisões gerenciais e operacionais de uma empresa.

Assim, a realização desta pesquisa propiciou a geração de um conhecimento em relação ao custo integrado e a importância desse sistema dentro das empresas. Contudo, aponta-se como proposta de pesquisas futuras a implantação do sistema de custo integrado com o restante da contabilidade, para que possa permitir uma visão quantitativa dos custos de cada setor, sendo diretos ou indiretos, produtivos ou administrativos. Além disso, possibilitar avaliar a rentabilidade dos produtos, bem como a fixação de preços.

\section{REFERÊNCIAS}

BEULKE, Rolando e BERTÓ, Dalvio José. Gestão de Custos. 1. ed. São Paulo: Saraiva, 2005.

BIASIO, Roberto. O uso de técnicas de gestão de custos e de preços para tornar as empresas competitivas e lucrativas sem entrar na guerra de preços baixos. Revista Contabilidade e Informação, 2014.

BOMFIM, Eunir de Amorim; PASSARELLI, João. Custos e formação de preços. São Paulo, SP: Editora Thomson IOB, Ed, v. 4, 2006. 
CREPALDI, Silvio Aparecido. Contabilidade gerencial: teoria e prática. Editora Atlas SA, 2002.

DAVIS, Mark M.; CHASE, Richard B.; AQUILANO, Nicholas J. Fundamentos da administração da produção. Bookman, 2001.

GUERRIGE, Miguel. Integração do Sistema de Custos com a Contabilidade Geral. Revista de Administração de Empresas, 1978.

IUDÍCIBUS. Introdução à teoria da contabilidade: para o nível de graduação. Atlas, 2009.

LACERDA, Daniel Pacheco et al. Algumas caracterizações dos métodos científicos em Engenharia de Produção: uma análise de periódicos nacionais e internacionais. XXVII Encontro Nacional de Engenharia de Produção, 2007.

LANG, Theodore. Accounting Cost Handbook. NY, USA: The Ronald Press Company p. 271 com adaptações, 1977.

MARTINS, Eliseu et al. Contabilidade de custos. São Paulo: Atlas, 2003.

MONZO, Milton. Sistema de Custo-Padrão e Análise de sua Contribuição ao Processo de Gestão Estratégica de Custos. Tese de Mestrado, UNIFECAP - Centro Universitário Álvares Penteado, São Paulo, 2003: 170 p.

MOREIRA, Daniel Augusto. Produção e Operações. São Paulo: Pioneira, 2015. NAKAGAWA,Masayuki. Gestão estratégica de custos:conceitos, sistemas e implementação. 1991.

OHNO, Taiichi. Toyota production system: beyond large-scale production. crc Press, 1988.

OISHI, Michitoshi; FONTANINI, Carlos Augusto Candêo. MJIT-Manutenção por Just in Time: manutenção otimizante realizada no tempo exato baseado em condições operacionais. Production, v. 7, n. 1, p. 75-83, 1997.

PADOVEZE, Clóvis Luís. Curso básico gerencial de custos. São Paulo: Pioneira Thomson Learning, 2003.

PEREZ, José Hernandez Jr., OLIVEIRA, Luís Martins, COSTA, Rogério Guedes. Gestão Estratégica de Custos. São Paulo: Atlas, 2000.

SCHIER, Carlos Ubiratan Da Costa. Gestão de custos. Editora Ibpex, 2011.

TUBINO, Dalvio Ferrari. Manual de planejamento e controle da produção. Atlas, 1997. 